\title{
A new species of Gnathoxys (Coleoptera: Carabidae: Carabinae) from an urban bushland remnant in Western Australia
}

\author{
Nadine A. Guthrie \\ Department of Environment and Conservation, Wildlife Research Centre, \\ POBox 51, Wanneroo, Western Australia 6946, Australia \\ Email: Nadine.Guthriendec.wa.gov.au
}

\begin{abstract}
Gnathoxys pannuceus sp. nov is described and illustrated from a specimen collected from Woodman Point Reserve, Western Australia. It is distinguished from other Gnathoxys species by the highly distinctive wrinkled pattern on the elytral surface, a feature that immediately distinguishes it from all other members of the genus.
\end{abstract}

\section{INTRODUCTION}

The ground beetle genus Gnathoxys Westwood 1842 is endemic to Australia and 16 species are currently recognised. The majority of these species occur in the southwestern region of Western Australia and seven occur along the MurrayDarling River system (Moore et al. 1987). Gnathoxys punctipennis Macleay 1873, also occurs along the southern coastal regions between southwest Western Australia into the South Australian Gulf region. Two species have not been seen since initial collection: G. irregularis Westwood 1842, reported from Port Essington in the Northern Territory by Westwood (1842) and G. sulcicollis Sloane 1910, from central Australia (no type locality was reported for this species; Moore et al. 1987).

Since initial collection, little has been determined about the ecology, taxonomic relationships or distributions of the various species within Gnathoxys. Generic relationships are not clear; however, Macleay (1864) suggested tentative associations between $G$. tesselatus Macleay 1864 and Promecoderus based upon the dilation of the male fore tarsus. Roig-Juñent (2000) however, determined that within the Broscitae, Gnathoxys forms a natural grouping with the other Australian endemic genera Cerotalis, Adotela and Brithysternum and is only distantly related to other genera (including Promecoderus, Creobius and Cascellius) within the subtribe Creobiina of the Broscitae. Gnathoxys is unique among this group and is defined by possessing fore tibia with two medial teeth, fore and middle tibia markedly palmate, and maxillary and labial palpal apical segments of males securiform (Roig-Junent 2000).

The broscitines are diverse and medium sized ground-dwelling beetles distributed in temperate, subarctic and subantarctic regions of the world, and are generally absent from the tropics (Davidson and
Ball 1998). Within Australia, the group is an important element in the beetle fauna of arid areas (Matthews 1980). There are 11 recognised Australian genera, with all species endemic, but two genera are represented by other species outside of Australia (Moore et. al. 1987).

A recent survey of urban bushland remnants in Perth, Western Australia surveyed a number of sites in the metropolitan area and a large number of carabid specimens, including several species of Gnathoxys, were collected in pitfall traps (How et. al. 1996; Guthrie 2001). Amongst these samples was a single representative of an unusual new species of Gnathoxys collected from Woodman Point, south of Perth. The distinctive appearance of the elytral sculpturing of this specimen is sufficient to suggest that this represents a new species, and the species is named and described in this paper.

\section{MATERIALS AND METHODS}

The specimen was collected using wet pitfall traps along a 100 metre transect set with an ethylene glycol mix $(400 \mathrm{ml}$ of $70 \%$ ethylene glycol, $30 \%$ water). The specimen was stored in $75 \%$ ethyl alcohol until identification and removal of the genitalia, and then pinned. The specimen is lodged in the Western Australian Museum, Perth (WAM).

Measurements were taken using a stereo microscope with vernier callipers and expressed in millimetres. Body length was measured from the apical margin of the labrum to the apex of the elytra (T-L). Length of pronotum was taken along the midline $(\mathrm{P}-\mathrm{L})$. Fore tibia length was measured from the femur joint to tip of 1 "tibial tooth (FT-L).

The gross genital morphology was examined by relaxing the specimen in a mixture of soapy distilled water and $2 \%$ acetic acid. The genitalia were then dissected out and cleared overnight in 
cold $10 \%$ potassium hydroxide. Once cleared, the $\mathrm{pH}$ of dissected parts was neutralised in dilute acetic acid. The dissected male genitalia were placed in glycerine for examination (Liebherr 1990).

\section{SYSTEMATICS}

\section{Family Carabidae}

\section{Subfamily Carabinae}

\section{Tribe Broscitae}

\section{Genus Gnathoxys Westwood, 1842}

\section{Type species}

None designated by Westwood, but originally included nominotypical species: Gnathoxys granularis Westwood, 1842; Gnathoxys irregularis Westwood, 1842. Gnathoxys granularis Westwood, 1842 by subsequent designation of Roig-Juñent (2000).

\section{Gnathoxys pannuceus, sp. nov.}

\section{Figures 1-7}

\section{Material examined}

\section{Holotype}

Male, Woodman Point Reserve, Western Australia, site WP2 [3207'50"S $\left.115^{\circ} 45^{\prime} 28^{\prime \prime E}\right]$, wet pitfall trap, 4 November 1994-19 January 1995,

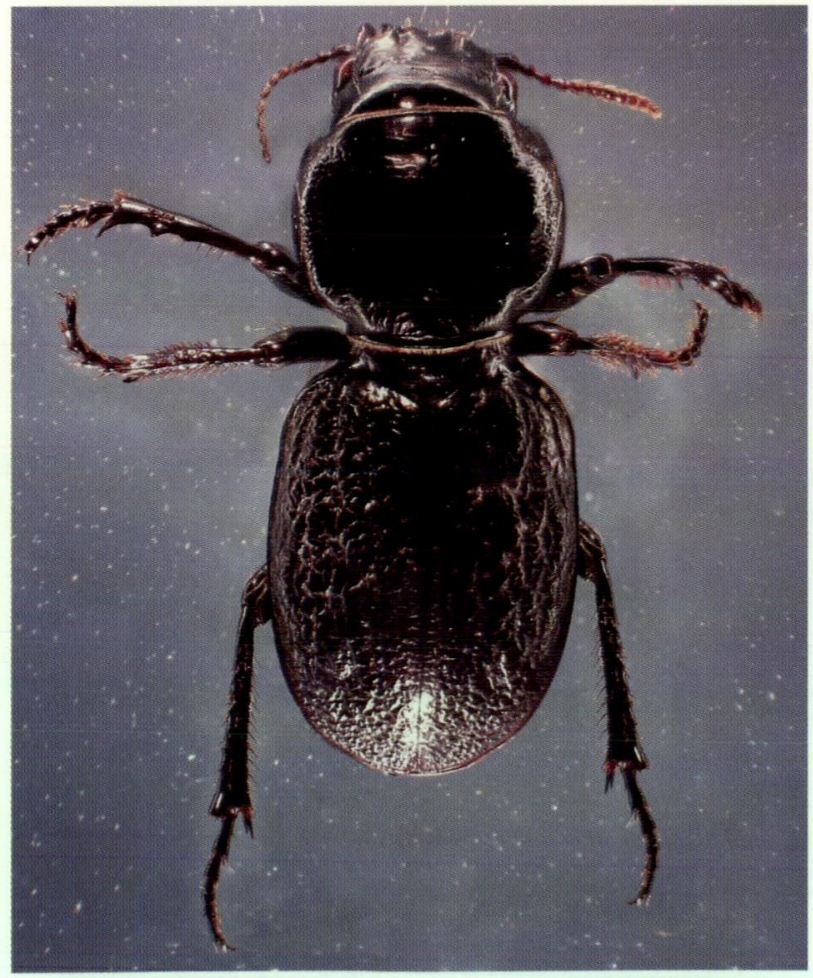

Figure 1 Dorsal habitus of Gnathoxys pannuceus holotype; male total length $13.3 \mathrm{~mm}$ collected by J. M. Waldock and M. S. Harvey (WAM \#38293).

\section{Diagnosis}

Gnathoxys pannuceus is similar in overall appearance and size to $G$. crassipes Sloane but is distinguished from all other Gnathoxys species by being heavy in appearance with a large head relative to overall size. The pronotum is strongly globular in shape with a distinct medial sulcus and faint wrinkles on the otherwise smooth dorsal surface. The pronotum and elytra margins have fine long setae in greater abundance than other similarly sized Gnathoxys. The most obvious character that separates this species from all others in the genus is the striking elytral pattern. Whereas G. granularis has distinct granulated areas on the elytra, and other Gnathoxys species possess elytral patterns consisting of foveae, punctures or similar depressions, this species has a highly distinctive wrinkled pattern.

\section{Description}

\section{Male (holotype) (Figures 1, 2)}

Total length $=13.3 \mathrm{~mm}$; elytral length/width $=7.6$ / $5.9 \mathrm{~mm}$; pronotum length $/$ width $=4.3 / 5.1 \mathrm{~mm}$; head length $=3.0 \mathrm{~mm}$; fore tibia length $=2.9 \mathrm{~mm}$. Colour entirely black without bronze or olive sheen, with dark orange eyes.

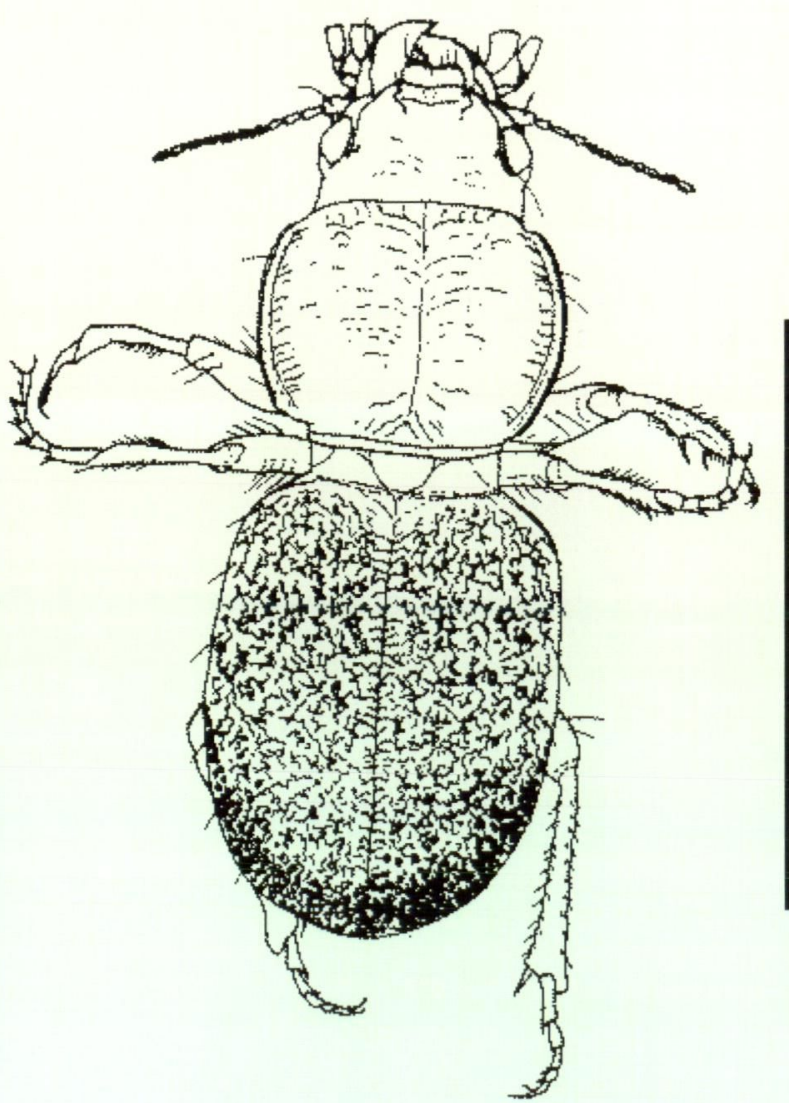

Figure 2 Detail of dorsal view of Gnathoxys pannuceus holotype; scale bar $=10 \mathrm{~mm}$ 
Head. Very long, heavy mandibles approximately $2 / 3$ of head length, slightly curved downward. Inner mandible edge straight and toothless, curved toward apex with deep overlap of mandible apices. Mandibular groove wide and shallow, approximately half mandible length, mandibular ridge very narrow. Single seta at groove apex and non-setiferous puncture on outer curve of mandibles near apex. Single seta on medial surface of $2^{\text {nd }}$ segment of palp and on ventral surface of basal segment of maxilla palp. Maxillae and labial apical palp segments securiform. Two fine setae on anterior mentum medial margin and one on either side of extremities of basal maxilla. Labrum slightly broader than long, bifid and rounded. Medial sulcus extremely faint. A fringe of setae on under side of labial anterior margin and three pairs of setae on labial dorsal anterior margin. Outer labrum edges yellow with remainder reddish brown. Eyes round, convex and not prominent or overly large. Antenna short, moniliform with single seta on scape and segments 4-11 covered dorsally and ventrally with thick short setae. Supraorbital seta posterior to eye, with supraorbital sulcus running forward, terminated posterior to mandibular ridge. Deep latero-medial sulcus on either side of head, initiated in line with anterior half of eye, extended directly forward to lateral extremities of clypeus. Clypeus medially and anteriorly depressed, with one mid and two lateral creases medially aligned.

Prothorax. Pronotum very rounded, sub-spherical with very weak extensions at cervical collar insertion point. Narrow pronotal margin with setae in anterior and posterior third of margin. Medial sulcus extended forward to anterior margin. Lateral wrinkles traverse pronotum surface, strongest near medial sulcus, lateral margins and towards thickened and blunt basal margin. Prosternum with wrinkles around sparse cluster of setae in front of each leg (widest anteriorly), wrinkles continue onto proepimeron, tubercles reduced to slight swollen areas between anterior coxa.

Pterothorax. Elytra are sub-quadrate, slightly longer than broad with rounded sides and apex. Peduncle thick and short with heavy shoulders projecting. Elytral margin very thin, with five setae evenly spaced along anterior two thirds of margin. Apical declivity finely granulated, extending over posterior one sixth of elytra. Granulations extending along lateral margins, diminished anteriorly. Four setae evenly spaced along dorsal edge of apical declivity on each elytron. Dorsal surface of elytra finely creased and wrinkled with extremely irregular sulci, reminiscent of "crumpled aluminium foil re-flattened" (Figure 3).

Abdomen. Ventrites bipunctate medially, with final seta pair positioned on medial portion of apical margin.

Legs. Foreleg: Trochanter ventral surface with one

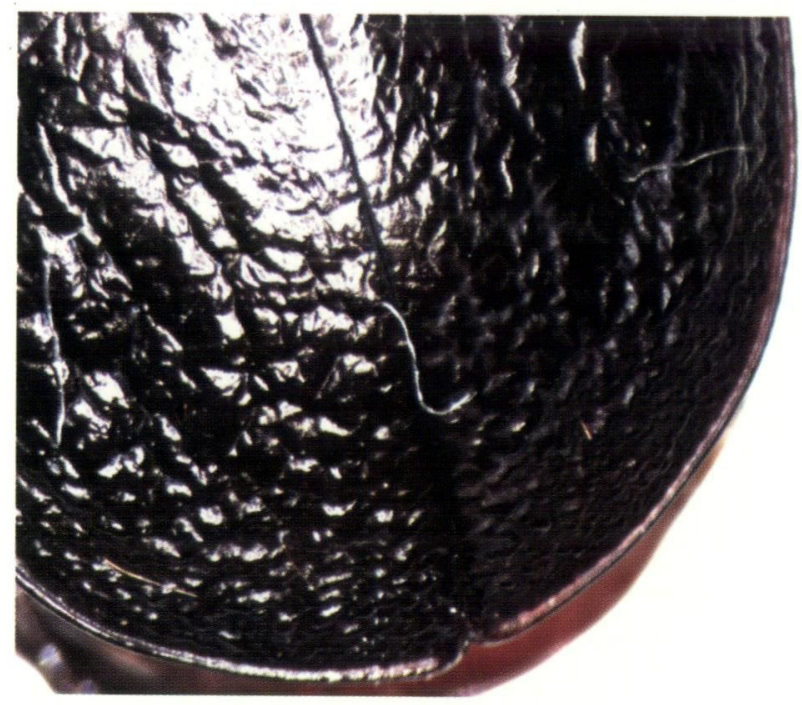

Figure 3 Gnathoxys pannuceus sp. nov. Detail of apical elytral surface showing extremely irregular sulci.

punctate seta. Femur with one cluster of setae on anterior ventral edge, two setae on posterior ventral edge, three setae on centre of posterior dorsal edge and a cluster centrally positioned on dorsal surface. Two teeth present on outer fore tibial edge, medial one smaller, both with a seta positioned on posterior distal margin. Linear arrangement of three setae along midline in line with antennal cleaning organ. A row of fine setae along inner edge of tibia terminated at cleaning organ. Rounded, flattened apical tooth directed distally. Tarsomeres triangular with outer lateral edge extended, narrowed distally towards $2^{\text {nd }}$ tarsomere. Three or four stiffened setae on both tarsomere edges. Apical tarsomere filiform with 2 setae on lateral edges, tipped with symmetrical short curved claws.

Midleg: Coxae with a cluster of setae on anterior surface, one seta on ventral surface, and one ventrally on trochanter. Clusters of setae present on anterior, dorsal and posterior femoral surfaces. Femur widened dorso-ventrally. Tibia with linear rows of stiff setae orientated distally on anterior and posterior surfaces. A triangular apical tooth with stiffened setae forming a fringe around distal surface of tibia at tarsus insertion point. Two similar sized apical teeth inserted below tarsus. Tarsal arrangement identical to foretarsus.

Hindleg: Coxae with two setae on apical and basal margins. Cluster of setae on posterior and dorsal surfaces of trochanter. Long setae in curved linear clusters on posterior and ventral surfaces of femur. Long setae sparsely distributed on distal ventral and dorsal third of femur. Tibia elongate, flattened with widened distal end. Rounded apical tooth on tibia broad and short. Tibia edge serrated weakly, serrations with rounded points. Stiffened short setae in linear rows thickly cover tibial surfaces. 

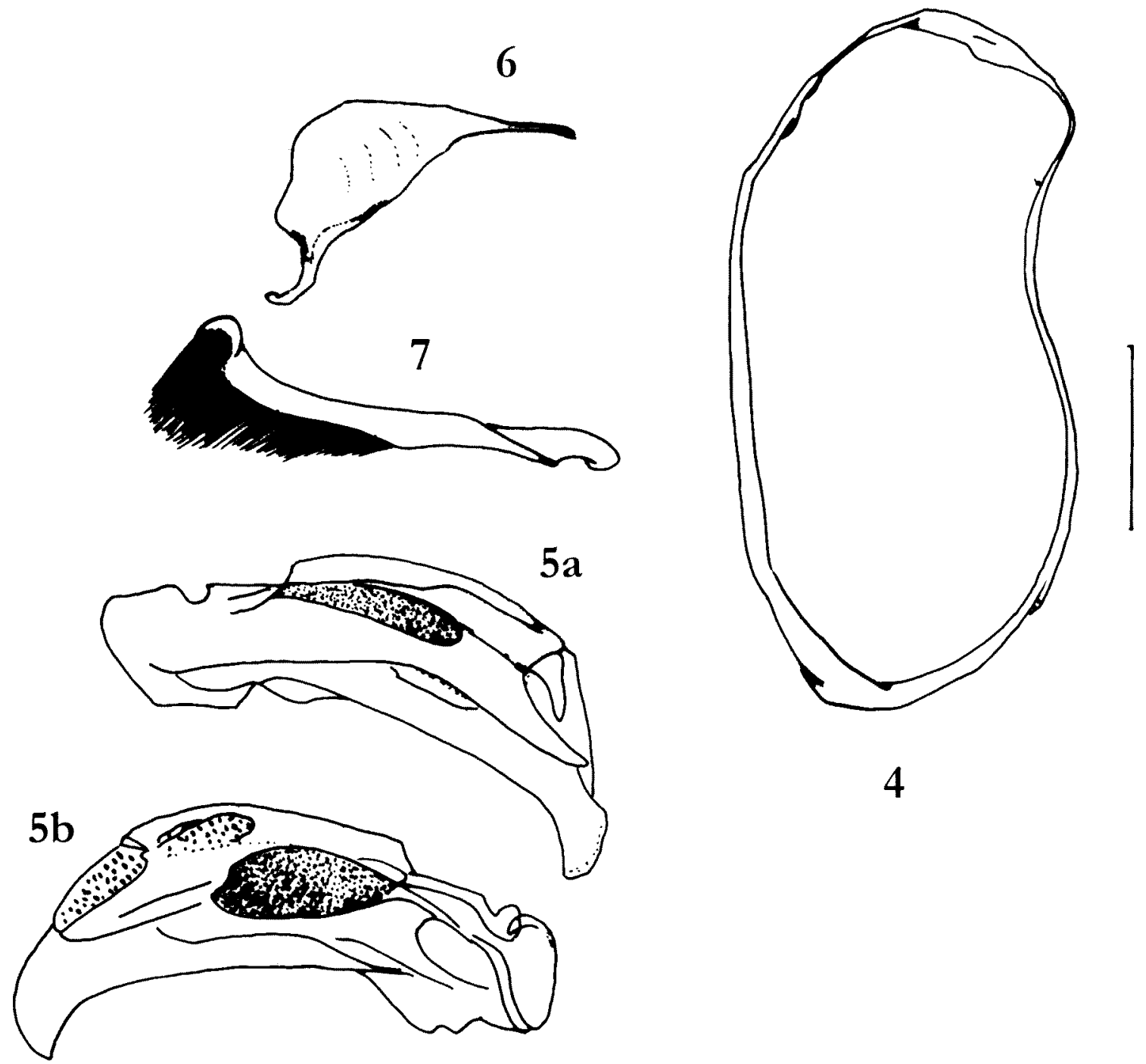

4

Figures 4-7 Gnathoxys pannuceus sp. nov. 4, genital ring; 5a, right (dorsal) view median lobe; $5 \mathrm{~b}$, left (ventral) view median lobe; 6 , left paramere; 7 , right paramere; scale bar $=1 \mathrm{~mm}$

Shortened apical teeth, equal in length set below tarsal insertion point. Tarsal arrangement identical to anterior tarsus.

Male Genitalia. Genital ring ovoid in shape, with slight concavity towards basal third, and thin edges and no extensions (Figure 4). Median lobe (Figure $5 a, b)$ thick, with no curvature and a small hook at apex. Orifice dorsally placed behind apex. Left and right sides of median lobe not symmetrical, with left (or ventral view) extended on upper surface near orifice. Parameres dissimilar (Figures 6, 7), left with extension on inner edge, extended to apical third of paramere. Right paramere larger and thicker, with thick setal brush extended from apex to mid-length, almost equal to adeagus in length.

Female: Unknown.

\section{Etymology}

The specific epithet is derived from the Latin adjectival pannuceus (lesser ragged, wrinkled, shrivelled) pertaining to the characteristic dorsal surface of the elytra.

\section{Remarks}

Gnathoxys pannuceus sp. nov. was collected from the type locality at Woodman Point and, although the pitfall traps were left open for twelve months, only a single specimen was collected. Searches at the type locality during the same season over several years have failed to locate any further specimens, suggesting that this species is locally uncommon or inhabits a microhabitat that is not effectively sampled through pitfall traps.

Numerous unidentified forms of Gnathoxys exist in collections (Western Australian Museum, Agriculture W.A. and the Australian National Insect Collection; author's unpublished observations). Sloane (1898) listed several unidentified Gnathoxys specimens but his descriptions and comments are too brief to satisfactorily ally any of the descriptions with these unidentified forms. It is also highly likely that more species of Gnathoxys will be collected in poorly surveyed areas of southwestern Australia. Therefore, a comprehensive revision of the genus 
incorporating all available material, including currently undescribed forms and the old types is required immediately.

\section{ACKNOWLEDGEMENTS}

I thank M.S. Harvey and J.M. Waldock for access to the carabid specimens collected during the Ground Fauna of Urban Bushland Remnants in Perth Survey. Thanks also to T. Houston, A. Szito and $T$. Weir for access to carabid beetle collections at the Western Australian Museum, Department of Agriculture, WA and Australian National Insect Collection, Canberra. I also thank B.P. Moore for bringing to $\mathrm{my}$ attention the significance of this unusual specimen. Jane McRae kindly photographed the holotype for me. Finally, I thank my supervisors, Pierre Horwitz (Edith Cowan University) and Mark Harvey for their unending advice and support throughout this project.

\section{REFERENCES}

Davidson, R.L. and Ball, G.E. (1998). The tribe Broscini in Mexico: Rawlinsius papillatus, new genus and new species (Insecta: Coleoptera: Carabidae) with notes on natural history and evolution. Annals of the Carnegie Museum 67 (4): 349-378.

Guthrie, N.A. (2001). Aspects of the Taxonomy and Ecology of Ground Beetle (Carabidae) Assemblage on the Swan Coastal Plain (with particular reference to habitat fragmentation on the Quindalup Dune System). Masters Thesis, Edith Cowan University.

How, R.A., Harvey, M.S., Dell, I. and Waldock, J.M. (1996). Ground Fauna of Urban Bushland Remnants in Perth. Unpublished Report to the Australian Heritage Commission. liebherr, J.K. (1990). A new tribal placement for the Australasian genera Homethes and Acolodermus (Coleoptera; Carabidae: Odacathini). Pan-Pacific Entomologist 66 (4):312-321.

Macleay, W.J. (1864). On the scaritidae of New Holland. $2^{\text {mut }}$ paper. Transactions of the Entomological Societ of New South Wales 1: 134-154.

Macleay, W.J. (1873). Miscellanea entomologica. Transactions of the Entomological Society of New South Wales 2: 319-370.

Matthews, E.G. (1980). A guide to the genera of Beetles of South Australia. Part 1 Archostemata and Adephaga. Special Educational Bulletin Series South Australian Museum, Adelaide

Moore, B.P., Weir, T.A. and Pyke, J.E. (1987). Rhysodidae and Carabidae. Pp20-320. In D.W. Walton (ed). Zoological Catalogue of Australia. Volume 4. Coleoptera: Archostemata, Myxophaga and Adephaga, 444pp. (Canberra: Australian Government Publication Service).

Roig-Junent, S. (2000). The subtribes and genera of the tribe Broscini (Coleoptera: Carabidae): cladistic analysis, taxonomic treatment, and biogeographical considerations. Bulletin of the American Museum of Natural History 255: 1-90.

Sloane, T.G. (1898). On Carabidae from West Australia sent by $\mathrm{Mr} \mathrm{A}$. M. Lea (with descriptions of new genera and species, synoptic tables, etc). Proceedings of the Linnean Society of New South Wales 23: 444520.

Sloane, T.G. (1910). Studies in Australian Entomology. No. XVI New species of Carabidae. Proceedings of the Linnean Society of New South Wales 35: 378-406.

Westwood, J.O. (1842). On the Scaritideous beetles of New Holland. Pp 81-90 pl. 24 In I.O. Westwood. Arcana Entomologica or illustrations of new rare and interesting insects, London: Smith Vol 1 iv $192 \mathrm{pp}$.

Manuscript receined 29 April 2005; accepted 10 July 2006 